\title{
Testicular pain as an initial complaint in patient with classic form of Klinefelter's syndrome: a case report
}

\section{S. Jelić1,2, A. Jević-Ivanović ${ }^{1}$, S. Živković ${ }^{1}$}

Identifier/Topic: EP-1315/ Clinical case reports - thyroid/others

${ }^{1}$ Clinical Hospital Center Bežanijska kosa, Clinic for Internal Medicine, Endocrinology Department, Belgrade, Serbia;

${ }^{2}$ School of Medicine, University of Belgrade, Belgrade, Serbia

Background:

Case report:
In spite of being the most frequent genetic form of male hypogonadism, Klinefelter's syndrome is not so rarely undiagnosed until adulthood. As the severity of manifestations in Klinefelter's syndrome is proportional to the number of additional $\mathrm{X}$ chromosomes, they seem less severe and apparent in its classic form, with a 47,XXY karyotype than in cases of this syndrome with mosaicism and other variants.

A 25-year-old male was reffered for endocrinological evaluation by urologist because of the chronic testicular pain preventing effective testosterone replacement of already proven hypogonadism. Physical examination: normal height, long limbs, muscular weakness, reduced or completely absent hair in the androgendependent regions, clinical signs of testicular dysgenesis. Hormone measurements: ACTH, $37.74 \mathrm{pg} / \mathrm{ml}$; cortisol, 505.9 $\mathrm{nmol} / \mathrm{l}$; TSH, $1.81 \mu \mathrm{IU} / \mathrm{ml}$; fT4, $15.15 \mathrm{pmol} / \mathrm{l} ; \mathrm{LH}, 31,78 \mathrm{mIU} / \mathrm{ml}$; FSH, $53.39 \mathrm{mIU} / \mathrm{ml}$, free testosterone, $5.0 \mathrm{pg} / \mathrm{ml}$; PRL, 519.9 $\mathrm{mIU} / \mathrm{l}$; vitamin D, $21.25 \mathrm{ng} / \mathrm{ml}$.

Pituitary MRI: a profound arachnoid recessus hustling the pituitary toward the dorsum of the sella turcica;

Densitometry: osteopenia with the L1-L4 T-score of -2.7 and the hip $T$-score of -2.1;

Karyotype: the classic, 47,XXY form of Klinefelter's syndrome Treatment and follow-up: testosterone replacement with the close follow-up of its effects.

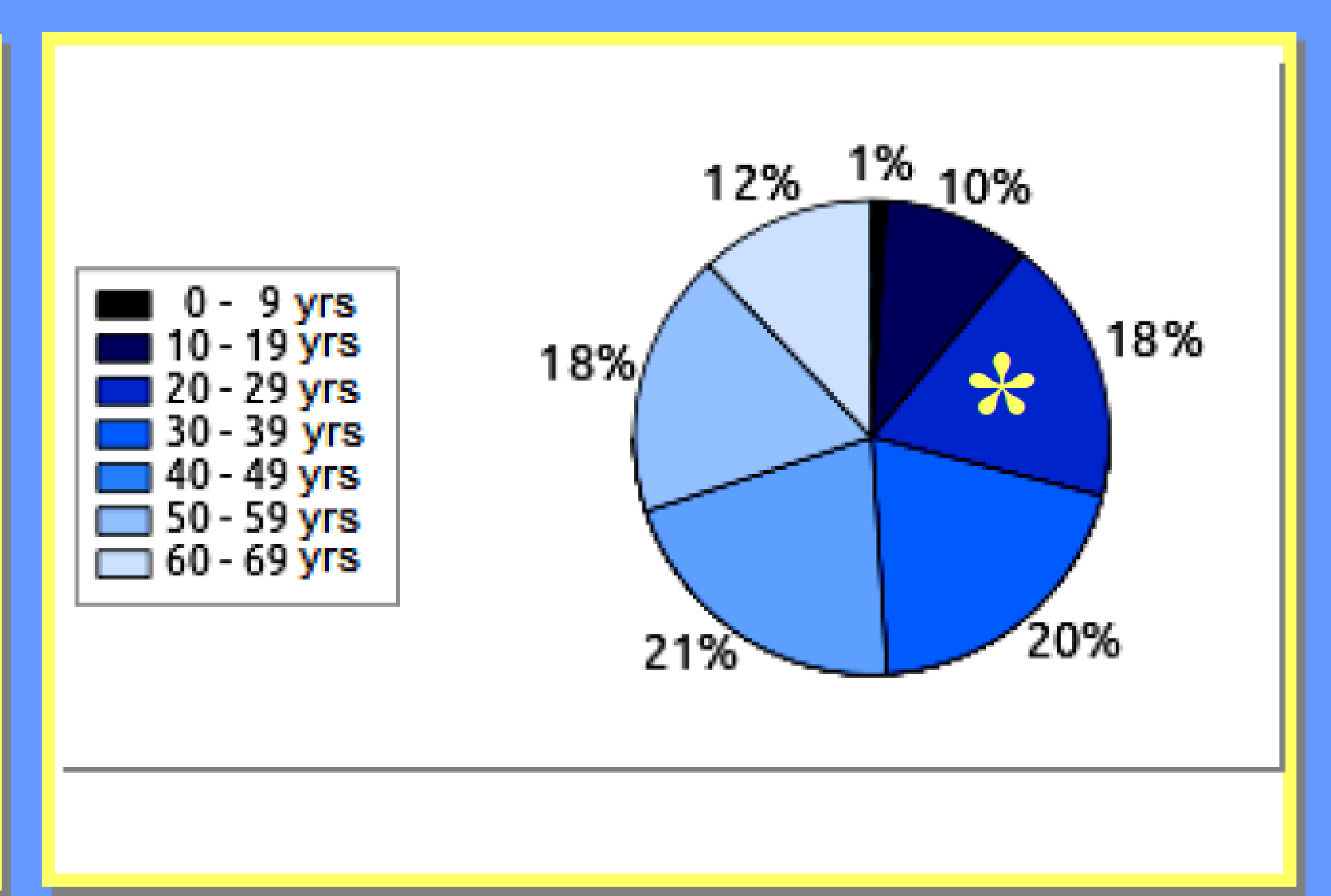

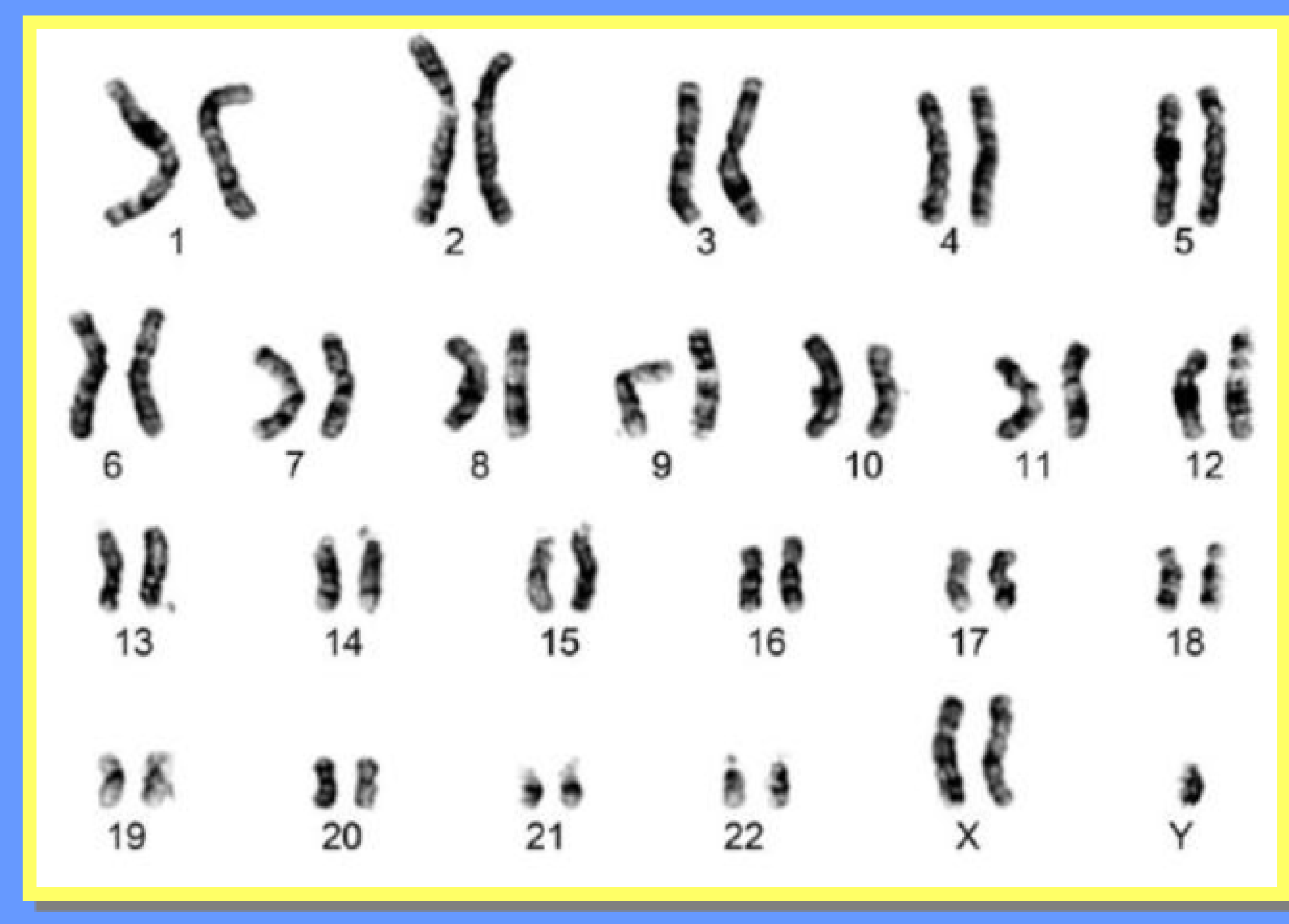

\section{Disscusion:}

Main issues for disscusion:

- Universal screening $v s$ case finding for earlier detection of dissorder;

- Necessity of well-programmed care and multidisciplinary approach;

- Timing of testosterone treatment, treatment options and regular checkups interval and coverage;

- Fertility issues and a need for obligatory genetic testing.

\section{Conclusions:}

References:
The case presented demonstrates a classical form of the Klinefelter's syndrome with not so classical presentation of testicular pain which halted the correction of proven androgen deficiency. Coexistant empty sella with hyperprolactinemia demand further periodical reassessment.
1.Herlihy AS, McLachlan RI. Screening for Klinefelter syndrome. Curr Opin Endocrinol Diabetes Obes 2015; 22(3): 224-9

2.Nieschlag E: Klinefelter syndrome: the commonest form of hypogonadism, but often overlooked or untreated. Dtsch Arztebl Int 2013; 110(20): 347-53.

3.Groth KA, Skakkebæk A, Høst C, Gravholt CH, Bojesen A. Klinefelter Syndrome - A Clinical Update. J Clin Endocrinol Metab 2013; 98: 20-30. 